\title{
Role of Imaging in a Case of Toxoplasmosis Presenting as Generalized Lymphadenopathy
}

\author{
Thara Pratap ${ }^{1, \odot}$ Muhammed Jasim Abdul Jalal ${ }^{2} \quad$ Vishnu A. K. ${ }^{1, \odot} \quad$ Senthil Raja ${ }^{3}$ \\ ${ }^{1}$ Department of Radiology, VPS Lakeshore Hospital, Kochi, Kerala, \\ India \\ 2Department of Internal Medicine and Rheumatology, VPS \\ Lakeshore Hospital, Kochi, Kerala, India \\ ${ }^{3}$ Department of Nuclear Medicine, VPS Lakeshore Hospital, Kochi,

\begin{abstract}
Address for correspondence Muhammed Jasim Abdul Jalal, MBBS, DNB, MNAMS, MRCGP, MRCP, Department of Internal Medicine and Rheumatology, VPS Lakeshore Hospital, Nettoor. P.O., Maradu, NH 47-Byepass, Kochi 682040, Kerala, India

(e-mail: jasimabduljalal@yahoo.com).
\end{abstract} Kerala, India

Indian J Radiol Imaging 2021;31:445-450.
Abstract
Keywords
- toxoplasmosis
- lymphadenopathy
- FDG PET
- infection
- lymph nodes

Toxoplasmosis is caused by Toxoplasma gondii an obligate protozoan intracellular parasite. The disease has variable prevalence globally and is usually asymptomatic. Pregnant and immunocompromised people are at risk of getting infected. Enlarged lymph nodes are the most frequently observed clinical form of Toxoplasma in humans, mostly affecting posterior cervical nodes. Other organs usually affected are the brain and eyes. We present a case of toxoplasmosis with generalized lymphadenopathy mimicking metastasis in a lady with a previous history of operated pancreatic neoplasm.

\section{Introduction}

Toxoplasmosis is considered a neglected tropical disease with a variable seroprevalence among woman of child-bearing age pan-India, ranging from $8.8 \%$ in Western India to $37.3 \%$ in Southern India. ${ }^{1}$ It is caused by Toxoplasma gondii. Human infection can be through ingestion of inadequately cooked infected meat, ingestion of oocysts contained within feces of infected cat, or by transplacental spread from a woman to her fetus. Common clinical manifestations include lymphadenopathy, fever, malaise, or hepatosplenomegaly. Diagnosis of toxoplasmosis lymphadenitis is made by cytology and serology. Toxoplasma lymphadenopathy in immunocompetent patients normally resolves without treatment.

\section{Case Report}

A 50-year-old female presented with epigastric and periumbilical pain of 5 days duration. She had undergone distal pancreatectomy and splenectomy for mucinous cystic neoplasm

published online July 28,2021
DOI https://doi.org/ $10.1055 / \mathrm{s}-0041-1734226$ ISSN 0971-3026 of pancreas 14 years back. She was a diabetic on huminsulin and oral hypoglycemic agent. She had a recent history of urinary tract infection for which she took antibiotics. Routine blood investigations were normal. CRP was negative and Ca19-9 was within normal limits. CT scan of the abdomen was done which showed multiple varying sized enlarged lymph nodes in the peri-pancreatic and para-aortic region and a lytic lesion involving L1 vertebral body. Based on the CT findings possibility of disseminated malignancy was considered. She was further evaluated with a PET-CT to delineate the extent of disease. PET-CT ( - Figs 1-6) showed variably hypermetabolic prominent lymph nodes in bilateral peri-parotid, bilateral cervical, right supraclavicular, mediastinal, right hilar, bilateral axillary, deep pectoral, abdomino-pelvic, and bilateral inguinal regions.

Following are the standardized uptake value (SUV) max values of lymph nodes in each region:
1. Right cervical SUV Max: 3.7
2. Left cervical SUV Max: 3.8
3. Right supraclavicular SUV Max: 2.4

(C) 2021. Indian Radiological Association

This is an open access article published by Thieme under the terms of the Creative Commons Attribution-NonDerivative-NonCommercial-License, permitting copying and reproduction so long as the original work is given appropriate credit. Contents may not be used for commercial purposes, or adapted, remixed, transformed or built upon. (https://creativecommons.org/licenses/by-nc-nd/4.0/).

Thieme Medical and Scientific Publishers Private Ltd. A-12, Second Floor, Sector -2, NOIDA -201301, India 
4. Right axillary SUV Max: 4.0

5. Left axillary SUV Max: 3.0

6. Mediastinal SUV Max: 3.2

7. Abdominal SUV Max: 2.5

8. Right inguinal SUV Max: 2.5

Possibility of lymphoproliferative or granulomatous disease was considered in view of bilateral deep cervical and mediastinal nodes. L1 vertebral body lesion was metabolically inactive and was in favor of hemangioma (-Fig. 7).

Patient underwent excision biopsy of axillary lymph nodes. There were two lymph nodes measuring 3.5 and $2 \mathrm{~cm}$ in greatest dimension with whitish cut section. Histopathology of the lymph nodes showed hyperplastic reactive lymphoid follicles with germinal

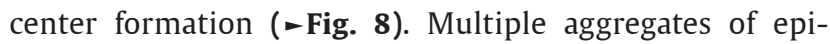
thelioid cells were noted encroaching the lymphoid follicles with moth eaten appearance (-Fig. 9). No necrosis was seen. Loose aggregate of epithelioid cells was seen in the high-power view (-Fig. 10). No inclusions were seen within the histiocytes. No well-formed granulomas were seen as in sarcoidosis. Special stains-periodic acid-Schiff (PAS), Gomori methenamine silver (GMS), and acid-fast bacilli (AFB) were negative, ruling out tuberculosis and infections like histoplasmosis. Histopathology findings of florid reactive hyperplasia with multiple aggregates of epithelioid cells encroaching the lymphoid follicles with moth eaten appearance are suspicious of toxoplasmosis.
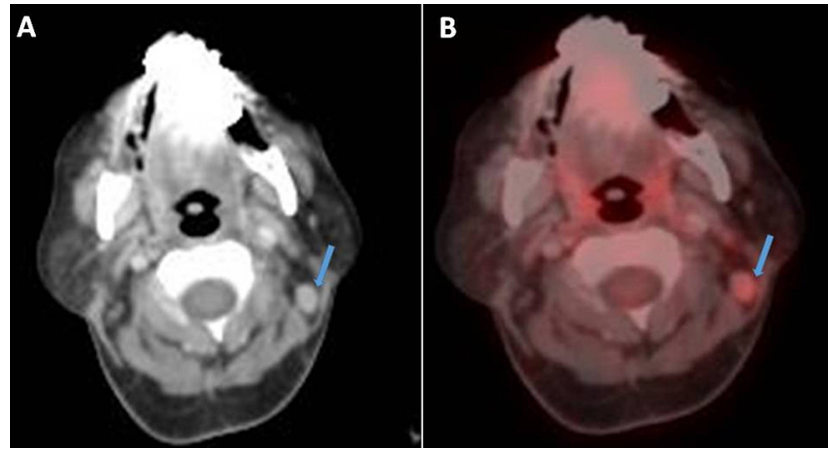

Fig. 1 CT (A) and FDG PET (B) showing hypermetabolic prominent lymph node in the left peri-parotid region. $\mathrm{CT}$, computed tomography; FDG PET, fluorodeoxyglucose-positron emission tomography.

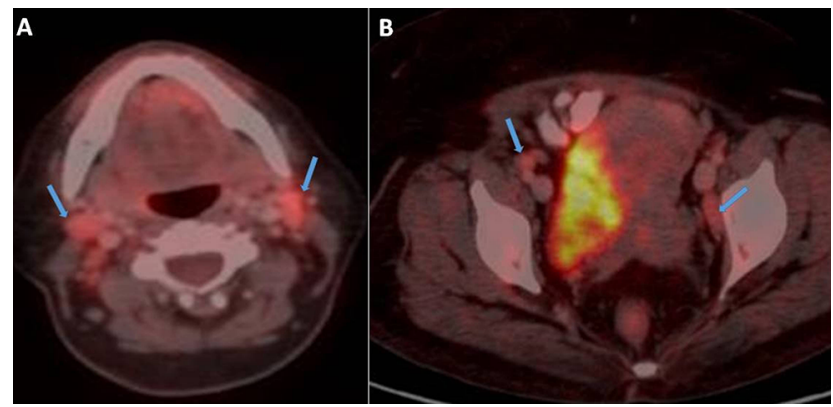

Fig. 2 FDG PET showing multiple hypermetabolic prominent lymph nodes in the bilateral cervical (A) and pelvic (B) regions. CT, computed tomography; FDG PET, fluorodeoxyglucose-positron emission tomography.
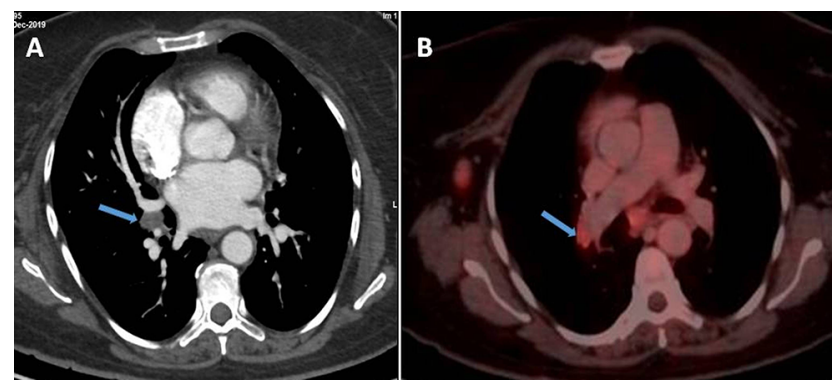

Fig. 3 CT (A) and FDG PET (B) showing hypermetabolic prominent lymph nodes in right hilar region. $\mathrm{CT}$, computed tomography; FDC $\mathrm{PET}$, fluorodeoxyglucose-positron emission tomography.

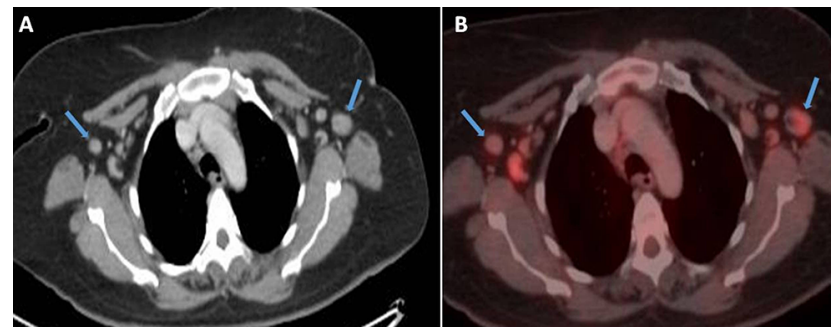

Fig. 4 CT (A) and FDG PET (B) showing multiple hypermetabolic prominent lymph nodes in the bilateral axillary regions. $C T$, computed tomography; FDG PET, fluorodeoxyglucose-positron emission tomography.

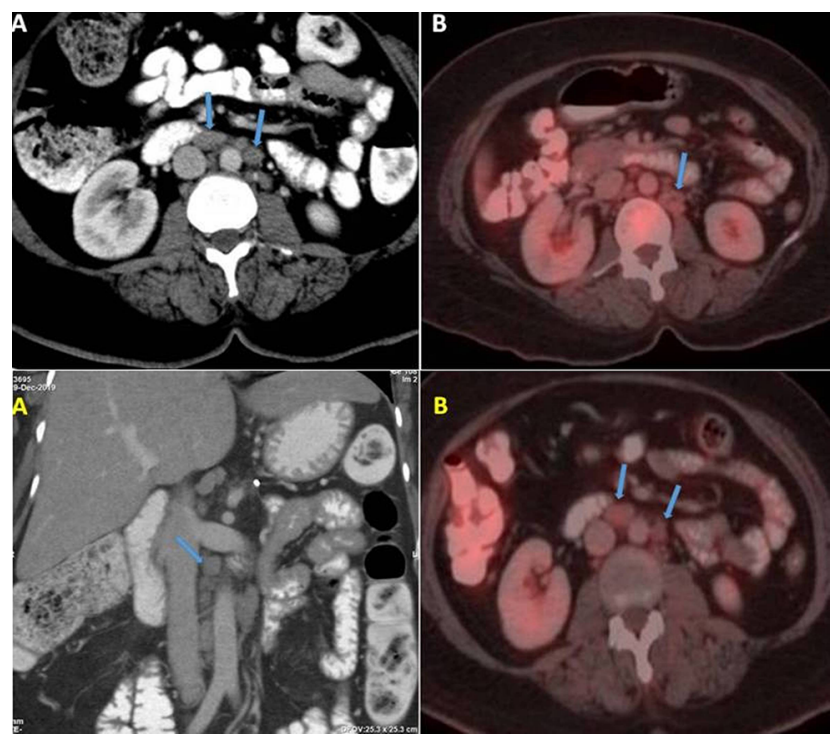

Fig. 5 CT (A) and FDG PET (B) showing multiple hypermetabolic prominent lymph nodes in the para-aortic (supra renal and infra renal level) region. CT, computed tomography; FDG PET, fluorodeoxyglucose-positron emission tomography.

She was further evaluated with IgG and IgM for Toxoplasma. Both of them were elevated (IgG was $>400 \mathrm{IU} / \mathrm{mL}$ and $\operatorname{IgM}$ was 51 ) with IgG avidity of $68.71 \%$ confirming the diagnosis. She denied history of having pets, involvement with animals, and ingestion of inadequately cooked meat.

Shewasmanaged withoraltrimethoprim-sulfamethoxazole and azithromycin for 1 month in regard to recurrent urinary tract infection, positive IgG, positive IgM, and high IgG avidity. 


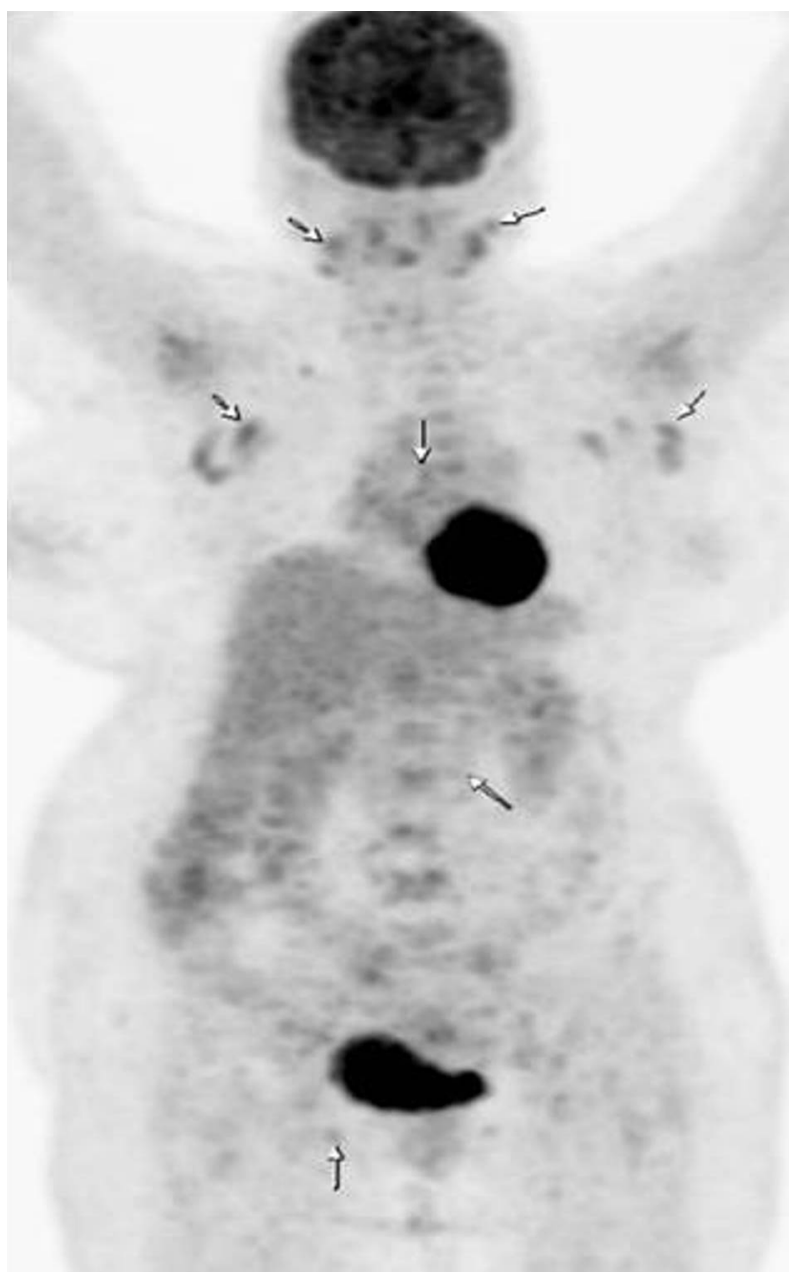

Fig. 6 FDG PET MIP image showing uptake in cervical axillary, para-aortic and right inguinal nodes. FDG PET, fluorodeoxyglucose-positron emission tomography.
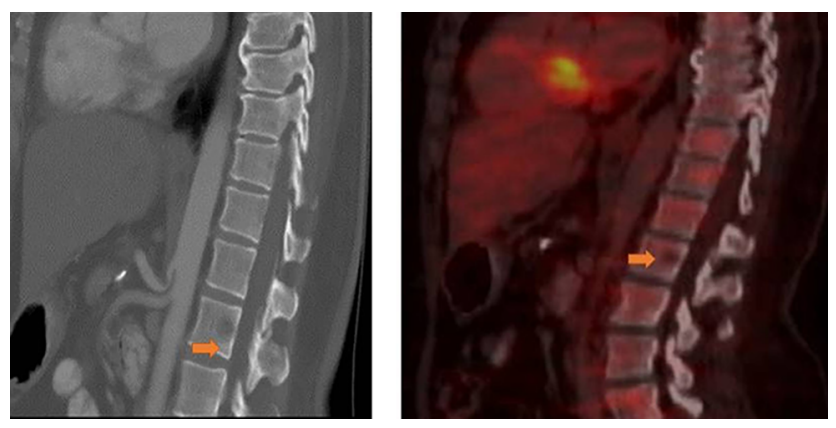

Fig. 7 Sagittal CT scan of lumbar spine showing non-FDG avid lesion L1 vertebra. CT, computed tomography; FDG, fluorodeoxyglucose.

After a month of treatment, IgG Toxoplasma was $36.5 \mathrm{IU} / \mathrm{mL}$ and IgM was 0.4 . She did not have urinary tract infections and abdominal pain during the course of treatment.

\section{Discussion}

Toxoplasma gondii is an obligate intracellular parasite which has three parasitic stages-a rapidly dividing tachyzoite, a slowly dividing bradyzoite, and an environmental sporozoite stage. Clinical manifestations of toxoplasmosis can be

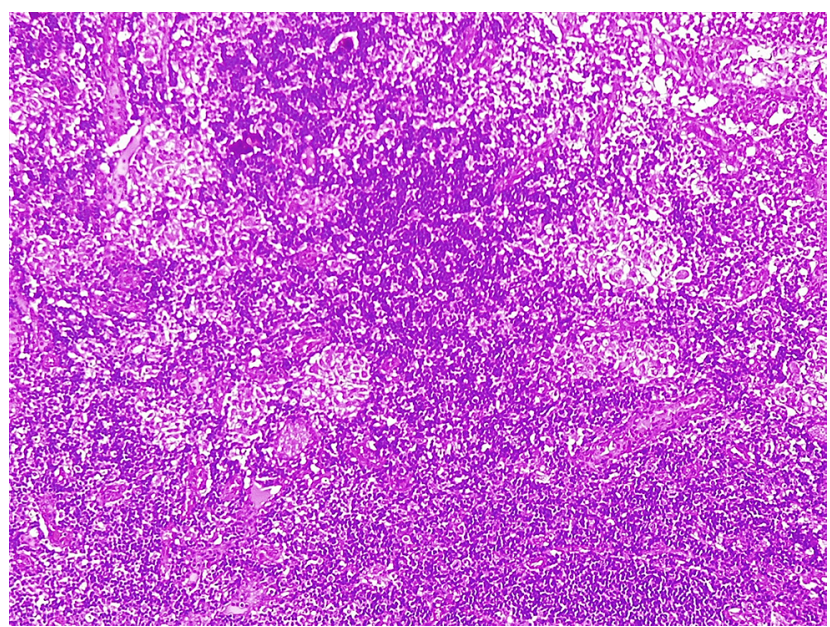

Fig. 8 Low power view showing multiple aggregates of epithelioid cells and aggregates of mononuclear cells.

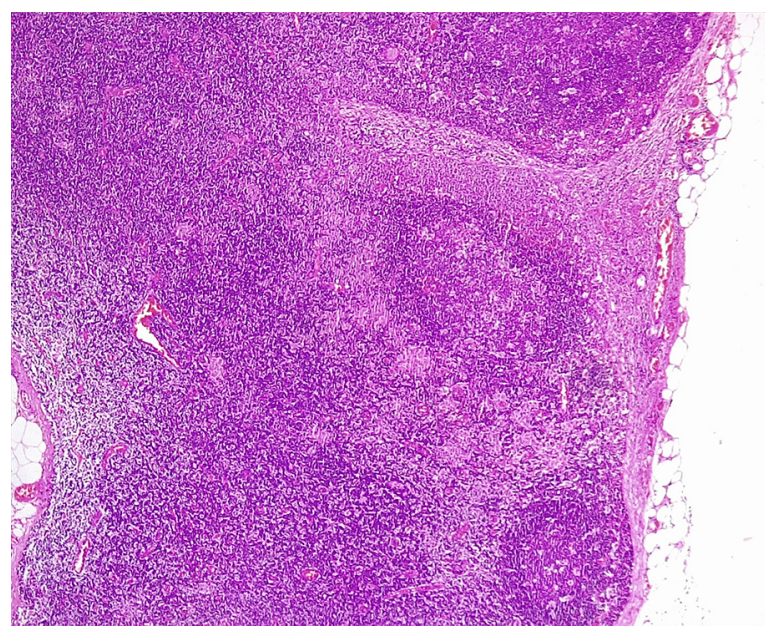

Fig. 9 Scanner view of lymph node showing hyperplastic reactive lymphoid follicles with germinal center formation. Multiple aggregates of epithelioid cells noted encroaching the lymphoid follicles.

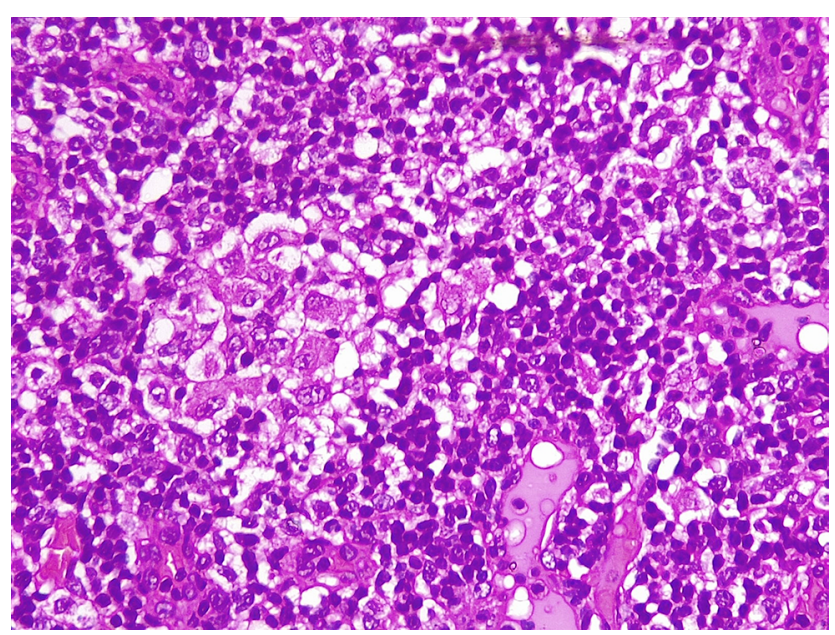

Fig. 10 High power view showing loose aggregate of epithelioid cells.

categorized as acquired toxoplasmosis, congenital toxoplasmosis, ocular toxoplasmosis, and cerebral toxoplasmosis. Acquired toxoplasmosis in an immunocompetent individual 
Table 1 Lymphadenopathy-differential diagnosis and imaging findings

\begin{tabular}{|c|c|}
\hline Differential diagnosis & Imaging findings \\
\hline Tuberculosis & $\begin{array}{l}\text { 1. Classical findings in CT include multiple enlarged lymph nodes with central low density due to } \\
\text { necrosis and peripheral enhancement though it can also be in the form of enlarged homoge- } \\
\text { neous lymph nodes, conglomerate nodes or calcified lymph nodes. }{ }^{4} \\
\text { 2. The characteristic pattern is mesenteric and peripancreatic lymph node group enlargement, } \\
\text { with multiple groups affected simultaneously. }{ }^{5} \\
\text { 3. Ancillary features like pulmonary involvement or other imaging evidences of extra nodal tuber- } \\
\text { culosis should increase the suspicion. }\end{array}$ \\
\hline Lymphoma & $\begin{array}{l}\text { 1. Imaging shows homogenously enhancing discrete or conglomerate lymph nodes on CT. } \\
\text { 2. Lymph nodes of Hodgkin's lymphoma are rarely seen in the mesentery (less than } 5-8.3 \% \text { ). } \\
\text { 3. Non-Hodgkin's lymphoma has a wide distribution including all sites of abdominal lymph nodes } \\
\text { and the mesentery is frequently involved (45\%) with conglomerate lymph nodes showing } \\
\text { sandwich sign. } \\
\text { 4. MRI shows diffusion restriction with characteristically low ADC values. } \\
\text { 5. Ancillary features like splenomegaly and complications like superior vena cava obstruction and } \\
\text { Horner's syndrome may be encountered. }\end{array}$ \\
\hline Leukemia & $\begin{array}{l}\text { 1. Differentiation from tuberculosis is made on imaging based on the involvement of lower para } \\
\text { aortic and inguinal nodes which are more common with lymphoproliferative disorders. } \\
\text { 2. Unlike TB, these lymph nodes usually do not exhibit central necrosis or peripheral enhance- } \\
\text { ment on contrast CT. }\end{array}$ \\
\hline Castleman's disease & $\begin{array}{l}\text { 1. The classic CT appearance of hyaline vascular Castleman's disease is that of a solitary enlarged } \\
\text { lymph node or localized nodal masses that demonstrate homogeneous intense enhancement } \\
\text { after contrast material administration. } \\
\text { 2. Hyaline vascular Castleman's disease can also manifest as mesenteric or retroperitoneal mass } \\
\text { with mild contrast enhancement. } \\
\text { 3. Non-enhanced CT may show classical arborising pattern of calcification in approximately } 15 \% \\
\text { of cases. } \\
\text { 4. Dynamic CT may show early rapid enhancement with delayed washout., }\end{array}$ \\
\hline Sarcoidosis & $\begin{array}{l}\text { 1. "Cluster of black pearls" (CBP) sign has a } p<0.001,83 \% \text { sensitivity, } 98 \% \text { specificity, } 91 \% \text { positive } \\
\text { predictive value, and } 96 \% \text { negative predictive value for differentiating sarcoidosis from other } \\
\text { lymphadenopathies. } \\
\text { 2. The CBP sign was considered present when tiny round nodules each measuring } 1 \text { to } 2 \mathrm{~mm} \text { were } \\
\text { seen distributed uniformly within the whole or part of the lymph node. }{ }^{11}\end{array}$ \\
\hline HIV infection & $\begin{array}{l}\text { 1. Imaging differentiation is difficult with histopathological examination necessary to rule out } \\
\text { opportunistic infections like tuberculosis. } \\
\text { 2. Diagnosis is confirmed by HIV ELISA or PCR study. }\end{array}$ \\
\hline $\begin{array}{l}\text { Connective tissue diseases } \\
\text { [SLE/Rheumatoid arthritis] }\end{array}$ & $\begin{array}{l}\text { Most of the cases will have musculoskeletal or pulmonary manifestations which may help in } \\
\text { establishing the diagnosis. }\end{array}$ \\
\hline
\end{tabular}

Abbreviations: ADC, apparent diffusion coefficient; ELISA, enzyme-linked immunosorbent assay; HIV, human immunodeficiency virus; PCR, polymerase chain reaction; SLE, systemic lupus erythematosus.

can be asymptomatic in $80 \%$ of the cases with rest of them being symptomatic.

Histopathology of lymph node in toxoplasmosis shows markedly hyperplastic lymphoid follicles with reactive germinal centers, clusters of epithelioid cells, and aggregates of monocytoid cells. ${ }^{2}$ The epithelioid cells seen single and in clusters, are scattered throughout the cortex and paracortex with encroachment by epithelioid cells on follicles and germinal centers. The epithelioid cells do not form round organized granulomas. No necrosis or fibrosis was seen. Multinucleated giant cells are not part of the toxoplasmic epithelioid proliferation.

Serological testing of toxoplasmosis is based on the presence of IgM and IgG antibodies, ideally in serial specimens 3 to 4 weeks apart. In acute stage, IgM antibodies are present while IgG antibodies may not be detectable. Seroconversion of $\operatorname{IgG}$ and $\operatorname{IgM}$ antibodies or a more than fourfold rise in
IgG antibody titer in sera run in parallel also suggests acute infection.

Toxoplasmosis can manifest as extensive lymphadenopathy and can mimic conditions like lymphoma or metastasis. ${ }^{3}$ Disseminated malignancy was considered as differential in our patient in the initial contrast-enhanced CT study mainly because of the past history of a mucinous pancreatic neoplasm and due to the presence of a lytic lesion in L1 vertebrae. Mucinous tumors of pancreas are of varying malignant potential which are treated surgically. However, metastatic mucinous cystadenocarcinomas are very rare.

Common differential diagnosis for a patient presenting with infra-diaphragmatic and supra-diaphragmatic lymphadenopathy includes:

1. Lymphoproliferative disorders like lymphoma and leukemia

2. Tuberculosis 
3. HIV

4. Disseminated malignancies

Other rare causes include

1. Atypical lymphoproliferative disorders like Castleman's disease

2. Hypersensitivity syndromes

3. Connective tissue diseases

4. Other granulomatous diseases like cryptococcosis, histoplasmosis and cat scratch disease.

Medications causing generalized lymphadenopathy include ${ }^{4}$

1. Allopurinol

2. Atenolol

3. Captopril

4. Carbamazepine

5. Cephalosporins

6. Hydralazine

7. Penicillin

8. Phenytoin

9. Pyrimethamine

10. Quinine

11. Sulfonamides

Unlike cerebral toxoplasmosis, there are no definite imaging features for Toxoplasma lymphadenitis. Imaging is instrumental in detection as well as characterization of superficial and deep lymphadenopathy and thereby providing a reasonable differential diagnosis ( $\mathbf{-}$ Table $\mathbf{1})$. $^{5-12}$

Imaging plays an important role in distinguishing benign from malignant adenopathy. Ultrasound using high frequency linear probes can effectively characterize superficial lymph nodes. Features favoring malignancy include increase in size, rounded morphology, asymmetrical cortical thickening, absence of hilum, heterogeneous echo texture, irregular margins, and peripheral vascularity on color Doppler. Apart from size criteria, cross-sectional imaging may show an evidence of necrosis and round morphology and is better suited for the assessment of deep lymph nodes like para-aortic and mediastinal groups.

Reticuloendothelial system-specific MRI contrast agents like ultrasmall paramagnetic iron oxides (USPIO) can be used to differentiate benign from malignant lymphadenopathy. Normal lymph nodes contain lots of macrophages which take up USPIO nanoparticles causing T2 shortening and there by low signal. Metastatic lymph nodes show high signal due to the absence of macrophages.

FDG PET is currently in the forefront of nodal staging in disseminated malignancies and lymphoproliferative disorders. It utilizes the feature of lesion, aerobic glycolytic rate which is increased in malignant lymph nodes. ${ }^{13}$ Semiquantitative analysis of the metabolism is done by calculating maximum standard uptake value (SUVmax). ${ }^{14}$ Many false positives are described in FDG PET interpretation such as granulomatous diseases like tuberculosis and sarcoidosis, other atypical infections, granulation tissues surrounding tumors, radiation changes, and technical factors like misregistration artifacts. However, SUVmax when combined with CT imaging features like size and attenuation can improve the overall diagnostic accuracy. ${ }^{15}$ FDG PET is useful in discriminating benign from malignant lymphadenopathy. However, 40\% of FDG uptake occurs in nontumor tissue and infection is a common cause. Atypical infections like cyptococcosis and pneumocystis can also give rise to false positive FDG uptake.

In addition, FDG also accumulates at the sites of infection and inflammation with high target-background ratio, because cells involved in infection and inflammation, especially neutrophils and the monocyte/macrophage are able to express high levels of glucose transporters, especially GLUT 1. There is significant overlap of intensity of FDG uptake in infection/inflammation, benign tumors, and malignant lesions. Both visual interpretation and semiquantitative parameters like SUV are not convincing enough in differentiating these etiologies.

Few studies have shown that dual point PET imaging (early and delayed images) improves the accuracy of FDG PET in this scenario. This is based on the differences in the kinetics of FDG uptake between benign and malignant entities to differentiate between the two pathologic entities. The uptake of FDG in malignant tissues does not reach a maximum until 2 to 4 hours after FDG injection, whereas most inflammatory lesions or normal tissues typically achieve maximum uptake of the tracer within 1 hour. Malignant lesions tend to increase in intensity between the two scans, whereas benign lesions tend to remain stable or decrease slightly in intensity. However, few studies could not reproduce similar results, making this concept doubtful. ${ }^{16}$

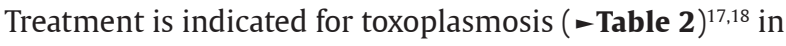
immunocompetent patients with acute Toxoplasma infection who have clinically significant myocarditis, myositis, hepatitis, pneumonia, brain lesions, or skin lesions. Treatment also is indicated in patients with Toxoplasma lymphadenitis accompanied by severe or persisting symptoms and in those with active ocular disease. In immunocompetent patients, treatment is prescribed for 3 to 4 weeks or until symptoms have subsided, whichever is longer.

Table 2 The drug regimen for toxoplasmosis in immunocompetent patients ${ }^{16}$

1. Pyrimethamine ( $100 \mathrm{mg}$ daily for 1 or $2 \mathrm{~d}$ and then $25-50$ mg daily) + sulfadiazine ( $1 \mathrm{~g}$ sixth hourly) + folinic acid (10-20 mg daily)

2. Pyrimethamine ( $100 \mathrm{mg}$ daily for 1 or $2 \mathrm{~d}$ and then $25-50$ $\mathrm{mg}$ daily) + clindamycin (300 mg q6h) + folinic acid (10-20 mg daily)

3. Pyrimethamine $(100 \mathrm{mg}$ daily for 1 or $2 \mathrm{~d}$ and then $25-50$ mg daily) + atovaquone (1,500 mg twice daily) + folinic acid (10-20 mg daily)

4. Pyrimethamine ( $100 \mathrm{mg}$ daily for 1 or $2 \mathrm{~d}$ and then $25-50$ mg daily) + azithromycin (250-500 mg daily) + folinic acid (10-20 mg daily)

5. Trimethoprim - sulfamethoxasole [TMP-SMX] (5/25-10/50 $\mathrm{mg} / \mathrm{kg} / \mathrm{d}$ in divided doses)

6. Intravitreal clindamycin $(1 \mathrm{mg})+$ dexamethasone $(400 \mu \mathrm{g})$ 


\section{Conclusion}

Generalized lymphadenopathy is a common clinical scenario encountered by a radiologist. Purpose of imaging is to arrive at a reasonable differential diagnosis and in differentiating benign from malignant causes of lymphadenopathy especially when nonpalpable or deep lymph nodes are involved. Proper understanding of the clinical history and a multimodality approach can improve the diagnostic accuracy. Since toxoplasmosis is a neglected tropical disease with variable prevalence across India, a high index of suspicion in relevant population can help in early diagnosis. Histopathological features in lymph node biopsies are suggestive of toxoplasmosis but are not diagnostic and should be combined with serology. Toxoplasmosis presenting as generalized lymphadenopathy is a rare entity and may be not usually considered in the differential of cervical adenopathy. We highlight a rare presentation of toxoplasmosis with extensive cervical, mediastinal and retroperitoneal adenopathy.

\section{Funding}

None.

\section{Financial Disclosure}

The authors have no financial relationships relevant to this article to disclose.

\section{Conflict of Interest}

None declared.

\section{Acknowledgments}

The authors would like to express our sincere gratitude to Dr. H. Ramesh, Dr. Pushpa Mahadevan, Dr. Vijayalekshmi Lekha, Dr. Rashmi R., and Dr. Arun Visakh. R for their guidance in this endeavor.

\section{References}

1 Singh S, Munawwar A, Rao S, Mehta S, Hazarika NK. Serologic prevalence of Toxoplasma gondii in Indian women of child bearing age and effects of social and environmental factors. PLoS Negl Trop Dis 2014;8(3):e2737

2 Saxena S, Kumar S, Kharbanda J. Toxoplasmosis submandibular lymphadenitis: report of an unusual case with a brief review. J Oral Maxillofac Pathol 2018;22(1):116-120

3 Ivanova K, Glatz K, Zippelius A, Nicolas G, Itin P. Acute toxoplasmosis mimicking melanoma metastases: review of conditions causing false-positive results on (18)F-FDG PET/CT. Dermatology 2012;225(4):349-353

4 Ferrer R. Lymphadenopathy: differential diagnosis and evaluation. Am Fam Physician 1998;58(6):1313-1320

5 Joshi AR, Basantani AS, Patel TC. Role of CT and MRI in abdominal tuberculosis. Curr Radiol Rep 2014;2(10):66-68

6 Burrill J, Williams CJ, Bain G, Conder G, Hine AL, Misra RR. Tuberculosis: a radiologic review. Radiographics 2007;27(5):1255-1273

7 Manzella A, Borba-Filho P, D'Ippolito G, Farias M. Abdominal manifestations of lymphoma: spectrum of imaging features. ISRN Radiol 2013;2013:483069

8 Frampas E. Lymphomas: basic points that radiologists should know. Diagn Interv Imaging 2013;94(2):131-144

9 Zhang G, Yang ZG, Yao J, et al. Differentiation between tuberculosis and leukemia in abdominal and pelvic lymph nodes: evaluation with contrast-enhanced multidetector computed tomography. Clinics (São Paulo 2015;70(3):162-168

10 Kligerman SJ, Auerbach A, Franks TJ, Galvin JR. Castleman disease of the thorax: clinical, radiologic, and pathologic correlation: from the radiologic pathology archives. Radiographics 2016;36(5):1309-1332

11 Ko SF, Hsieh MJ, Ng SH, et al. Imaging spectrum of Castleman's disease. AJR Am J Roentgenol 2004;182(3):769-775

12 Venkata Ramanan R, Pudhiavan A, Venkataramanan A. The "cluster of black pearls" sign of sarcoid lymphadenopathy: a new sign on thin-section contrast-enhanced multidetector CT. Clin Radiol 2017;72(9):729-736

13 Pantel AR, Ackerman D, Lee SC, Mankoff DA, Gade TP. Imaging cancer metabolism: underlying biology and emerging strategies. J Nucl Med 2018;59(9):1340-1349

14 Kitajima K, Suenaga Y, Minamikawa T, et al. Clinical significance of SUVmax in (18)F-FDG PET/CT scan for detecting nodal metastases in patients with oral squamous cell carcinoma. Springerplus 2015;4(1):718

15 Yu C, Xia X, Qin C, Sun X, Zhang Y, Lan X. Is SUVmax helpful in the differential diagnosis of enlarged mediastinal lymph nodes? A pilot study. Contrast Media Mol Imaging 2018;2018:3417190

16 Chen S, Li X, Chen M, Yin Y, Li N, Li Y. Limited diagnostic value of Dual-Time-Point (18)F-FDG PET/CT imaging for classifying solitary pulmonary nodules in granuloma-endemic regions both at visual and quantitative analyses. Eur J Radiol 2016;85(10):1744-1749

17 Dunay IR, Gajurel K, Dhakal R, Liesenfeld O, Montoya JG. Treatment of toxoplasmosis: historical perspective, animal models, and current clinical practice. Clin Microbiol Rev 2018;31(4):e00057-e17

18 Taila AK, Hingwe AS, Johnson LE. Toxoplasmosis in a patient who was immunocompetent: a case report. J Med Case Reports 2011;5:16 